Revista Iberoamericana, Vol. LXXXI, Núm. 250, Enero-Marzo 2015, 15-30

\title{
UN ASUNTO FAMILIAR: ENTRE AFECTO Y VIOLENCIA POLÍTICA EN $L A$ HORA AZUL DE ALONSO CUETO Y UN LUGAR LLAMADO OREJA DE PERRO DE IVÁN THAYS
}

POR

MatTHew Bush

Lehigh University

En las últimas tres décadas se ha producido dentro de las letras peruanas un número creciente de obras que intentan comprender la violencia política que vivió el país andino entre 1980 y 2000 . Entre las obras más logradas que tratan de este momento de violencia nacional, es posible distinguir dos tendencias narrativas organizadas alrededor de este periodo turbulento: la de una orientación neo-indigenista como Adiós Ayacucho (1986) de Julio Ortega y Rosa Cuchillo (1997) de Óscar Colchado Lucio; y la que ofrece un relato desde una perspectiva urbana -y más específicamente, limeña- como La hora azul (2005) de Alonso Cueto y Un lugar llamado Oreja de Perro (2008) de Iván Thays. ${ }^{1}$ Mientras las primeras novelas le presentan al lector historias de sustrato mítico para así problematizar las ramificaciones de la violencia nacional, las últimas se refugiarían en la figura narrativa de la familia para, aparentemente, intentar descifrar el sentido del conflicto armado interno.

En efecto, las novelas de Cueto y Thays emplean, en distintos grados, la estética del melodrama familiar para narrar relatos ambientados en el Perú después del final del enfrentamiento entre el gobierno y Sendero Luminoso. Lo que se vuelve aparente en la lectura de las dos novelas es la manera en que Cueto y Thays, apoyándose en una base melodramática, emplean un léxico y repertorio de imágenes acentuados emocionalmente para representar las experiencias y relaciones afectivas de las familias de sus respectivas historias, junto con identidades veladas y posibilidades de felicidad y realización personal dentro del seno familiar. El lenguaje emotivo que construye estas figuras narrativas comunes al melodrama familiar también coloca a los protagonistas ante una incesante necesidad de primero manifestar, y luego expiar, sus sentimientos de culpa. ${ }^{2}$ De hecho,

1 En cuanto a la segunda agrupación de obras que señalo, dos novelas que ofrecen miradas que tocan tangencialmente o espectralmente la capital peruana son Abril rojo (2006) de Santiago Roncagliolo y Lost City Radio (2007) de Daniel Alarcón.

2 Uso aquí el término "figura narrativa" siguiendo lo propuesto por Roland Barthes en A Lover's Discourse: Fragments (1979). Para Barthes, una serie de "figuras" como ansiedad, espera, declaración, celos y 
los sentimientos de remordimiento experimentados por los protagonistas de estas novelas se convierten en el eje narrativo alrededor del cual gira toda la acción de cada texto, conduciéndolos a peripecias en las que desentrañan poco a poco los traumas del pasado, mientras exponen sus más íntimos deseos y miedos. En este sentido, al emplear tales recursos melodramáticos para contar estas historias que dialogan con un momento de tumulto nacional, las narraciones de Cueto y Thays revelan el esfuerzo del melodrama para comprender procesos históricos abstractos en términos afectivos. De esta forma, el melodrama no se manifiesta como un estilo narrativo excesivo "de mal gusto", sino más bien como el formato narrativo que escenifica un acercamiento, directo y complicado a la vez, al periodo más conflictivo de la historia reciente del Perú.

El melodrama, pues, ofrece una forma particularmente aguda de analizar momentos complejos de conflicto social ya que representa ramificaciones de procesos históricos abstractos en un nivel más íntimo y personal. Como apunta Thomas Elsaesser "the persistence of melodrama might indicate the ways in which popular culture has not only taken note of social crises and the fact that the losers are not always those who deserve it most, but has also resolutely refused to understand social change in other than private contexts and emotional terms" (47) [la persistencia del melodrama tal vez indique las maneras en que la cultura popular no solo toma nota de las crisis sociales y el hecho de que los derrotados no son siempre los que más se lo merecen, sino cómo el melodrama ha rechazado entender el cambio social en términos que vayan más allá de contextos privados y emocionales (traducción mía)]. El melodrama, como observa Elsaesser, traduce lo que ocurre en un contexto más amplio en un escenario individualizado. El caso de La hora azul de Alonso Cueto ilumina precisamente este mecanismo afectivosocial que es movilizado dentro de la narración melodramática. ${ }^{3}$

La novela de Cueto cuenta la historia de Adrián Ormache, un abogado limeño perteneciente a la élite social, que descubre que su padre - el recientemente fallecido Alberto Ormache- había tenido una amante durante su estadía en Ayacucho como jefe de un cuartel que luchó contra Sendero Luminoso. Esta amante, Miriam Anco, había sido separada a la fuerza de su familia y permaneció un tiempo como prisionera del padre de Adrián, quien posiblemente la dejó embarazada antes de que ella escapara de su cautiverio. Adrián no puede descansar hasta descubrir la verdad de esta historia

remordimiento componen una gramática del relato romántico. Propondría que se puede utilizar esta serie de figuras de Barthes para identificar las herramientas del melodrama.

3 Aunque aquí Elsaesser habla específicamente del melodrama "popular" en un contexto europeo y estadounidense, se podría argüir que en el caso latinoamericano la distinción entre la llamada "alta" cultura y cultura popular se vuelve difusa. Desde las canónicas ficciones fundacionales latinoamericanas hasta las obras de consumo masivo como el folletín y la telenovela, se percibe una innegable sensibilidad melodramática compartida. En este sentido, no es extraño percibir un tono melodramático en las novelas de Cueto y Thays, las dos generalmente entendidas como obras de "alta" literatura.

Revista Iberoamericana, Vol. LXXXI, Núm. 250, Enero-Marzo 2015, $15-30$ ISSN 0034-9631 (Impreso) 
familiar, lo que lo conducirá a conocer turbias historias de la guerra contra Sendero, a mantener un amorío con la ex amante de su padre y finalmente a establecer una relación con Miguel, el hijo de Miriam y muy probablemente medio hermano de Adrián. Dadas la estructura policial de la novela y insistencia con la que Adrián Ormache lleva a cabo su investigación de la historia familiar, Victor Vich ha comentado que la novela de Cueto "es, en efecto, una alegoría destinada a nombrar la necesidad que tiene el país de conocer una verdad oculta" (235). Desde luego, como observa Vich, esta obsesión con la "verdad", producto de la culpa sufrida por Ormache, tiene un papel estructurador principal en la novela. Sin embargo, más que la lectura alegórica del Perú según la historia de la novela de Cueto, lo que quisiera proponer es una lectura alrededor de los contornos del melodrama familiar que enmarcan La hora azul.

En cuanto a la presencia de relatos familiares dentro del melodrama latinoamericano, Jesús Martín-Barbero propone la hipótesis de que "el enorme y tupido enredo de las relaciones familiares, que como infraestructura hacen la trama del melodrama, sería la forma en que desde lo popular se comprende y se dice la opacidad y complejidad que revisten las nuevas relaciones sociales"(131). Este acercamiento calza con la proyección familiar dentro de La hora azul, donde, hacia el final del texto, el protagonista se enfrenta a la posibilidad de que su hermanastro, fruto ilegítimo de una relación violenta entre su padre y Miriam, forme parte de su vida privilegiada. Así, la formulación melodramática que orienta La hora azul ofrece una versión de las múltiples secuelas del conflicto violento nacional que se dan dentro de una familia particular.

Resulta paradójico, sin embargo, que estas nuevas complicaciones dentro de la estructura familiar se manifiesten en una familia que podría pensarse, en un principio, como de las más alejadas de las manipulaciones sufridas durante la época de violencia en el Perú. Esta apreciación inicial se debe a que, por muchos años, las familias andinas sufrieron desproporcionadamente los efectos de la violencia política y los daños de la separación familiar, lo cual se encuentra ejemplificado en La hora azul en la representación del rapto de Miriam y la subsiguiente muerte de su familia debida a asociaciones con, y batallas contra, Sendero. Como observa Ponciano del Pino H. en sus estudios de caso en Ayacucho (bases senderistas en Sello de Oro, Viscatán y el Comité Popular Abierto del Río Ene), las familias que militaban en Sendero Luminoso sacrificaban a sus familias, y sus relaciones afectivas con ellas, a la causa revolucionaria, lo cual eventualmente creaba una reticencia entre algunos de los militantes. ${ }^{4}$ Así, la investigación de Del

4 Acerca de un incidente en la que algunos militantes senderistas en Sello de Oro desertan de su célula en parte a causa de sus preocupaciones familiares, Del Pino H. comenta que "the family, as the most important web of social and affective ties, managed to announce the end of the utopia-to break the grip of "total domination"” (183) [la familia, como la red más importante de nexos sociales y afectivos, pronunció el fin de la utopía - para romper la fuerza de la "dominación total" (traducción mía)]. De hecho, un correlato al estudio de Del Pino H. se encuentra en la antología de ficciones acerca de la época de

Revista Iberoamericana, Vol. LXXXI, Núm. 250, Enero-Marzo 2015, 15-30 ISSN 0034-9631 (Impreso)

ISSN 2154-4794 (Electrónico) 
Pino H. u otras enfocadas en el entorno andino podrían inducirnos a pensar que la descomposición familiar a raíz de la violencia nacional aparecería como un fenómeno propio de la sierra. En este sentido, un ilusorio binario andino/costeño-una característica común del imaginario peruano- percibiría que es en el primer polo donde se registran las complicaciones de la vida familiar; a la vez, se entendería que la segunda mitad del binario ofrecería alguna forma de estabilidad familiar. Esta constancia del hogar, sin embargo, no resulta ser el caso en la novela de Cueto. ${ }^{5}$

De hecho, a pesar de la evidente comodidad de la familia Ormache, descrita por Adrián al principio de la novela, pronto el lector se entera de que la madre de Adrián, Beatriz Ormache, ha fallecido, lo cual ha dejado un vacío en la vida de Adrián, quien siempre había vivido mucho más apegado a su madre que a su padre. Es esta muerte la que, en efecto, pondrá en marcha la serie de eventos que se desarrollan a lo largo de la novela, puesto que Adrián inicia la búsqueda de Miriam después de encontrar una carta acusatoria dirigida a su madre entre sus efectos personales después de su muerte. La autora de esta carta es Vilma Agurto, quien aduce tener fotografías de los delitos sexuales cometidos por el padre de Adrián en Ayacucho, lo cual en última instancia resulta ser un chantaje. Sin embargo, Adrián reconocerá al final de la novela el papel que tuvo su madre en iniciar su búsqueda de la historia familiar cuando comenta que "anoche, sentado solo en mi cama, pensé que la verdadera autora de esta historia es mi madre. El día que ella dejó la carta de Vilma Agurto en el baúl, lo cerró y se fue a su cuarto, me dejó escrito su testamento: averigua quién es esa chica, averigua quién fue de veras tu padre y quién eres tú y quién soy yo" (Cueto, Azul 299).

Este reconocimiento del papel de la madre en la pesquisa familiar que cumple Adrían sirve para ubicar a la familia en el núcleo del relato y lo hace de una forma que es patentemente melodramática. Además de depender de los rescates "justo a tiempo" para crear suspenso entre el público, el relato melodramático también hace uso del azar para poder avanzar la trama. ${ }^{6} \mathrm{El}$ melodrama, más frecuentemente en su vertiente policial, depende de la revelación de un dato oculto que cumple la función de aclarar más allá de cualquier duda la verdad de una situación cuya significación permanece velada a los personajes. El mecanismo melodramático es aun más efectivo si este dato oculto aparece

violencia en el Perú, Toda la sangre: Antología de cuentos peruanos sobre la violencia política (2006) recogida por Gustavo Faverón Patriau, donde el antologador observa que la violencia política tiene un impacto devastador en la representación de relaciones filiales (15-20).

5 La falta de estabilidad familiar que liga la sierra y la costa es también un elemento central del cuento "Pálido cielo" de Cueto donde un joven estudiante inmigrado de Ayacucho a Lima descubre los lazos que su familia mantenía con Sendero Luminoso a la luz del atentado en la calle Tarata en Lima en 1992.

6 Un caso notorio del azar melodramático en la novela de Cueto se encuentra en el escape de Miriam de su cautiverio: en la ausencia de Alberto Ormache, ella engaña a los guardianes del cuartel, saludándolos de lejos al pasar, vestida de militar, por la salida principal. Esto es posible debido a la coincidencia de que el alto tono de su voz se asemeja a la de Guayo, uno de los ayudantes de Alberto Ormache. 
de una forma inesperada, como una casualidad que se da con el propósito de ayudar al protagonista a desentrañar un vestigio de información de una situación misteriosa. Es precisamente este tipo de huella fortuita lo que Adrián descubre, lo cual lo conduce a indagar en su propia historia familiar.

Sin embargo, no es solamente un descubrimiento casual de información lo que impulsa a Adrián, sino también una profunda necesidad de expresarse y de ser comprendido, lo que es indicativo de la estética melodramática de la novela. ${ }^{7}$ De hecho, el impulso de revelarse ante un público está presente en la novela de una forma evidente, ya que el relato se cuenta en primera persona. La hora azul esencialmente le presenta al lector una biografía autorizada de Adrián Ormache, quien, desde un principio, es consciente de que está contando una historia profundamente personal para un público futuro. Explicando cómo llegó a ser abogado, Ormache escribe que:

De niño no sólo me interesaba el Derecho. Fantaseaba también con la idea de escribir. Escribí alguna vez una novela de aventuras y romances.

Desde hace unas semanas he pensado en mi vocación frustrada de escritor.

He pensado en eso porque ahora he querido contar esta historia. No sé por qué. Me protege no verle la cara a quien lea esto (hay un autor contratado para poner su maldito estilo y su nombre en este libro) (Cueto, Azul 14).

Desde este pasaje inicial de la novela, estamos ante una historia en la que se pretende la comunicación de eventos íntimos por los que Ormache se siente avergonzado. En este sentido, La hora azul nos ofrece un testimonio, o mejor, una confesión en la cual se presentan las experiencias personales del narrador, y principalmente, las condiciones afectivas de estos eventos. La novela de Cueto está escrita en un registro donde los estados emocionales del narrador están en el primer plano de su relato, lo que induce al público a sentir la historia, a experimentar simpatía o rabia, tristeza o felicidad de acuerdo con las acciones del protagonista. Es precisamente en este diálogo afectivo donde se puede localizar la dinámica melodramática de La hora azul. El melodrama en la novela de Cueto, cuya base es la intriga familiar, utiliza la representación de emociones para crear un puente entre el texto y el lector para así involucrar al público

7 Comenta Peter Brooks que "The desire to express all seems a fundamental characteristic of the melodramatic mode. Nothing is spared because nothing is left unsaid; the characters stand on stage and utter the unspeakable, give voice to their deepest feelings, dramatize through their heightened and polarized words and gestures the whole lesson of their relationship" (4) [el deseo de expresarlo todo parece ser una característica fundamental del modo melodramático. No se guarda nada porque se dice todo; los personajes toman el escenario y dicen lo impronunciable, les dan voz a sus emociones más profundas, dramatizando en sus palabras y gesticulaciones elevadas y polarizadas la moraleja de sus relaciones (traducción mía)]. La novela de Cueto compartiría esta necesidad de "expresarlo todo" para así dar sentido a la experiencia de Adrián Ormache.

Revista Iberoamericana, Vol. LXXXI, Núm. 250, Enero-Marzo 2015, $15-30$ ISSN 0034-9631 (Impreso) ISSN 2154-4794 (Electrónico) 
en el relato. De esta forma, el contenido político de la historia logra su mayor impacto, ya que el lector, identificándose con un entorno familiar sentimental, procesa con más eficacia los mensajes sociales codificados dentro del relato.

Dentro de esta fórmula familiar, se alude a otras pautas narrativas que también comparten una larga historia con el melodrama, pues como confiesa Ormache, de joven había escrito una novela de aventuras y romances, lo cual no parece estar demasiado lejos de los hábitos de lectura y escritura de Alonso Cueto. Años antes de haber escrito La hora azul, Cueto afirmó que:

Escribo historias policiales, excepto que tal vez sería mejor definirlas como historias de amor. O más bien como relatos de aventuras de familia. En todo caso son historias de suspenso. He sido un lector devoto de novelas policiales y de detectives [...] También he sido un lector de novelas de aventuras en países lejanos y de novelas de amor [...] El amor es el estímulo para la exploración y el descubrimiento en otras personas y en nosotros mismos (Testimonio 33).

Los hábitos de lectura de Cueto parecerían ofrecer las claves de una historia melodramática exitosa: un relato de aventura familiar, escrito para desarrollar un ambiente de suspenso, donde interceden aspectos de narrativa detectivesca y sentimental. Todos estos elementos narrativos participan del diálogo afectivo comentado anteriormente, puesto que activan en el lector sensaciones de anticipación que lo comprometen emocionalmente con el resultado de la historia. La hora azul manifiesta, pues, la combinación cohesiva de estos elementos narrativos, y el eslabón para conectar estas diferentes tendencias melodramáticas (familiar, policial, de aventuras, romántica) se encuentra precisamente en la culpa que experimenta Adrián Ormache.

En efecto, el arrepentimiento que experimenta Ormache por los actos de su padre en Ayacucho, y específicamente por la relación forzada que éste había mantenido con Miriam, sirve como el motivo principal de todas sus acciones en la novela. Sin embargo, Adrián enfrenta una situación bastante complicada, ya que lo ocurrido en Ayacucho pertenece al pasado, y no hay manera de intervenir para poner freno a las acciones cometidas por su padre. Las reivindicaciones de Adrián, entonces, toman otro matiz: puesto que no puede cambiar el pasado, busca mejorar el presente de las víctimas de su padre. Es allí donde se siembra el insistente deseo de "ayudar" a Miriam, y luego a su hijo Miguel. Sin embargo, lo que motiva a Adrián podría leerse en un principio como un instinto de auto-preservación. En una conversación con su amigo Platón Acha donde Adrián le comenta su deseo, todavía incomprendido por él mismo, de encontrar a Miriam, y el miedo a la culpa que podría heredar a causa de las transgresiones de su padre, Platón le sugiere:

Revista Iberoamericana, Vol. LXXXI, Núm. 250, Enero-Marzo 2015, 15-30 ISSN 0034-9631 (Impreso) 
-No sé, a mí me parece que tenemos la culpa. Son nuestros padres y nuestros hijos, no son unos cualquiera. Son como nosotros. No podemos librarnos de ellos.

-Pero no somos culpables de lo que hagan ellos, pues.

Sonrió. Puso los codos en la mesa y cruzó las manos.

-¿Y qué crees que te va a decir esa chica?

-Bueno... Quiero que ella me diga si mi papá fue tan desgraciado como dicen. Pero no es eso tampoco. No sé, la verdad. Quiero encontrarla. No quiero que difunda el asunto. A lo mejor la noticia puede trascender y eso no me conviene. También me siento mal, la verdad (Cueto, Azul 149).

En este primer instante, cuando Adrián opina que los pecados del padre no deberían ser imputados sobre el hijo, se plantea un asunto que es crucial para la novela, y para el melodrama en general. Aquí se presenta la idea, común dentro del melodrama familiar, que hasta que no haya orden en los asuntos familiares - con una armonía de sentimientos fraternales y filiales- no puede haber un final feliz para la familia. En este sentido, solo si Adrián decide asumir algo de la culpa por las acciones de su padre como le sugiere Platón -lo que ocurre, en efecto- podrá ayudar a expiar la culpa heredada por los Ormache. Esta posibilidad narrativa cuadra con la visión del melodrama familiar donde todo conflicto filial tiene que ser resuelto para alcanzar armonía y tranquilidad en el hogar, lo que en este caso esta íntimamente relacionado con eventos de violencia política. ${ }^{8}$ Así, dentro del seno de la familia Ormache, se ofrece una posibilidad de curar una herida dejada por la guerra contra Sendero Luminoso, lo cual se pretende lograr por medio de las buenas obras de Adrián.

No faltan ejemplos en la novela donde Adrián enfatiza que quiere ayudar a Miriam. Por ejemplo, cuando Paulino Valle, el ex jefe de Miriam en una bodega donde ella había trabajado tras llegar a Lima desde Ayacucho, le pregunta por qué quiere localizar a Miriam, Adrián responde que "Soy abogado, quiero hacer algo por ella", y que quiere "Ver si está bien y ayudarla si puedo" (Cueto, Azul 156). Sin embargo, lo que revelan las palabras de Adrián cuando por fin ubica a Miriam en un barrio del distrito de San Juan de Lurigancho iluminan y problematizan esta culpa que Ormache quisiera purgar. Cuando en uno de sus primeros encuentros Miriam le pregunta a Adrián por qué se

\footnotetext{
Esta coincidencia de preocupaciones familiares y políticas es común en el melodrama; como comenta Nina Gerassi-Navarro acerca del melodrama hispanoamericano decimonónico, "Family happiness was a consequence not only of healthy feelings, but, more importantly, of specific political ideals that built and sustained the prosperity of a blissful home. Hence the private world of the home became deeply entwined with the public world of politics" (152) [la felicidad de la familia es consecuencia no solo de sentimientos saludables, sino, más crucialmente, de ideales políticos específicos que construyeron y sustentaron la prosperidad de un hogar feliz. De ahí, el mundo privado del hogar se relacionó profundamente con el mundo público de la política (traducción mía)]. De una forma parecida, en la novela de Cueto, las acciones individuales representan en un nivel micro los pasos hacia una práctica de reconciliación en el Perú.
}

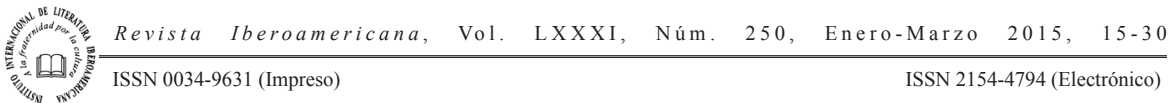


empeña en verla a pesar de que ella no piensa hacer pública la historia de los abusos que sufrió, Ormache le responde que "Lo que quiero es ayudarte-dije-. Nada más. Pero la verdad también es que lo hago por mí, o sea para sentirme mejor yo" (Cueto, Azul 216). En otras palabras, mientras Adrián le de ayuda a Miriam - en la forma de apoyo económico- también recibiría algo que no tiene precio: una conciencia tranquila. En este sentido, lo que lo motiva a Adrián no es un deseo desinteresado, sino un medio para sentirse mejor acerca de las acciones de su padre. La ayuda brindada a Miriam termina siendo, claramente en la conciencia de Adrián, una ayuda para sí mismo.

Esta "ayuda" llega a complicarse aun más cuando la relación entre Adrián y Miriam toma matices románticos. De hecho, este extraño cruce en el que Adrián y su padre terminan compartiendo una misma amante, aunque en periodos distintos, serviría para ilustrar los comentarios de Jesús Martín-Barbero acerca de la opacidad familiar y social mencionados anteriormente, y también para conectar padre e hijo en un sentimiento de culpa. Es relevante que el padre le mencione al hijo su amorío con la muchacha ayacuchana en su lecho de muerte y que le pida a Adrián que la busque -una escena de fuerte impacto dentro del esquema melodramático de la novela por su capacidad de escenificar último deseo del personaje. Adrián recibe este último pedido y, en efecto, sigue los pasos de su padre al mantener este amorío con Miriam, no sin ramificaciones tremendamente dañinas. ${ }^{9}$ Poco después de mantener su relación con Adrián, Miriam fallece de lo que es reportado como una complicación cardíaca, pero que parece ser un suicidio. La muerte de Miriam dejaría a Adrián, aparentemente, en una situación donde ya no podrá seguir exorcizado sus sentimientos de arrepentimiento. Sin embargo, Ormache encuentra otra forma de ayudarse al cuidar al hijo de Miriam, Miguel, quien es muy probablemente su medio hermano.

Nuevamente, Adrián es consciente de que ayuda a sí mismo al auxiliar a Miguel. Cuando le da dinero a la señora Melchor, quien cuida a Miguel después de la muerte de Miriam, reflexiona "Me hacía bien mostrarle el billete. Era un acto egoísta, como dármelo a mí mismo" (Cueto, Azul 269). Pese a ello, Adrián siente un impulso de seguir en la vida de Miguel, buscándole una psicóloga para que procese la muerte de su madre y ayudándolo también con sus gastos para el colegio. Cuando Miguel le pregunta a Adrián por qué ha tomado este interés especial en él, Adrián le comenta "algo así como que en el Perú había muchas diferencias sociales y económicas y que los que éramos más afortunados teníamos un deber con los que no lo eran tanto" (Cueto, Azul 287).

9 Acerca de este triángulo amoroso comenta Víctor Vich que, "Podríamos decir que luego de la muerte del padre, el lugar del poder queda vacío y entonces la novela narra cómo un nuevo sujeto se prepara para ocuparlo. Desde este punto de vista lo que no cambia es un cierto movimiento masculino: el padre la secuestra, luego Adrián la acosa. En ambos casos, Miriam siempre parece ser un objeto al que se le impone el deseo de otro" (239). 
Esta explicación resulta reveladora ya que, al final de la novela, el reconocimiento que recibe Adrián de Miguel pone en evidencia el abismo social que los divide.

En las últimas líneas de la novela, Miguel y Adrián conversan frente al mar y el primero, después de una pausa dramática donde mira el horizonte, le dice a Ormache "Quería agradecerle-dijo-. Agradecerle. Nada más" (Cueto, Azul 303). Esta conclusión no deja de ser problemática puesto que, como observa Víctor Vich, "Si en algún momento la posibilidad utópica fue fantaseada a partir de la relación entre Adrián y Miriam, todo ello termina disuelto cuando se muestra a Adrián y Miguel conversando al final de la novela: ahí cada uno es consciente de que la sociedad les ha asignado un lugar y que casi están completamente sujetos a él" (245). En efecto, como comenta Vich, el final de la novela sirve para restaurar una distancia social insondable, aunque lo que vemos es un final feliz para Ormache. A fin de cuentas, Adrián recibe el anhelado reconocimiento que buscaba en sus varios intentos de ayudar a Miriam y Miguel; esta gratificación permite que se lave de algo de la culpa heredada de su padre, y pone en escena la resolución común del melodrama familiar. ${ }^{10}$ No es casual que este anhelado agradecimiento coincida con la resolución de los conflictos familiares de los Ormache después de que Claudia, la esposa de Adrián, se había distanciado al enterarse de su amorío con Miriam. Esta reconciliación familiar también incluye ahora a Miguel, que forma una parte suplementaria de la familia Ormache.

En este sentido, el final de la novela calza plenamente con el enfoque del melodrama familiar. Esto demuestra nuevamente la centralidad de la realización de la felicidad hogareña de los Ormache, lo cual cuestiona si estamos en realidad ante una novela de las víctimas. Es decir, aunque la novela sirve para arrojar luz sobre este momento de violencia política en el Perú e incluye a sectores desfavorecidos fuertemente impactados por el conflicto con Sendero Luminoso, lo hace siempre desde y para la clase media limeña. Es, pues, la estructura del melodrama familiar-forma estética históricamente predilecta de la burguesía nacionalista- la que una y otra vez enfatiza las relaciones familiares como el núcleo del relato, lo que se logra por medio de la representación de conflictos emocionales. Este énfasis en el aspecto afectivo del relato no puede sino mostrarnos el privilegio del sujeto cuya relación con la violencia nacional esta mediada por un acercamiento emocional y reflexivo en vez de una aproximación física y frontal ante una agresión directa; así, es Adrián el que está obsesionado con querer sentirse mejor, mientras Miriam, víctima directa de la violencia, prefiere callar sus emociones y seguir adelante.

El enfoque particular en las relaciones afectivas y familiares, sin embargo, no le resta relevancia política a La hora azul. Por el contrario, en la novela de Cueto, lo personal y

\footnotetext{
10 Acerca de la centralidad del reconocimiento de la virtud, comenta Peter Brooks que el melodrama ofrece "un drama de reconocimiento" en el que la virtud de los protagonistas inicialmente es cuestionada, pero eventualmente reconocida (27).
}

Revista Iberoamericana, Vol. LXXXI, Núm. 250, Enero-Marzo 2015, $15-30$ ISSN 0034-9631 (Impreso) ISSN 2154-4794 (Electrónico) 
lo familiar están puestos en contacto con lo político, lo cual pone en evidencia el aspecto analítico del melodrama familiar. El melodrama hace de la emoción doméstica una emoción política, pero siempre dentro de un recinto privado, íntimo. En este sentido, el resultado de un melodrama familiar como La hora azul no es una panacea alegórica para lidiar con un momento de crisis social, sino un pequeño paso, un micro relato que da una visión de un mundo donde se presentan aproximaciones a la reconciliación. Esta conexión entre lo personal y lo político que se percibe en la novela de Cueto, sin embargo, se diferencia de lo que se observa en Un lugar llamado Oreja de Perro de Iván Thays donde el enfoque narrativo es más explícitamente personal.

Quizás debido a la proximidad cronológica de su publicación o por su éxito editorial -las dos novelas participaron en el prestigioso concurso Premio Herralde de la Novela, ganado por Cueto y donde Thays resultó finalista-, existe una tendencia crítica a leer $L a$ hora azul y Un lugar llamado Oreja de Perro en diálogo. De hecho, como se percibe en varias lecturas de la novela de Cueto, también parecería que la novela de Thays exigiera una lectura alegórica. Esta aproximación a Un lugar llamado Oreja de Perro es quizás más problemática de lo que sería en el caso de La hora azul, ya que Thays ha afirmado en varios momentos su consciente alejamiento del realismo (social) en las letras peruanas. ${ }^{11}$ Sin embargo, sobre Un lugar llamado Oreja de Perro, Thays ha comentado que tuvo el claro propósito de "escribir algo que portara un mensaje o que dijera algo sobre las cosas que pasan, pero no con un compromiso ideológico" (Entrevista sin pág.), lo cual pondría en contacto la narración autoreflexiva de la novela con el entorno social tocado por la violencia política. En esta clave Luis Hernán Castañeda lee la novela de Thays notando que la relación sostenida entre el narrador de la historia y una muchacha lugareña "permite la identificación de las subjetividades individuales y la producción de una comunidad discursiva terapéutica, en la cual la memoria colectiva se somete a una purificación y una exteriorización: se deja organizar y relatar" (273). Este acercamiento a Un lugar llamado Oreja de Perro parecería encarnar el proyecto de comunicar un mensaje sin ser directamente ideológico, un logro que Roberto Ruz había detectado en el estilo metaliterario empleado en la novelística de Thays anterior a $U n$ lugar llamado Oreja de Perro para caracterizarse como un tipo de arte "alto" dirigido hacia un público lector culto (77).

Sin embargo, aunque lecturas de esta índole puedan resaltar el comentario sociopolítico implícito en la obra de Thays, no se puede negar que el núcleo de Un lugar llamado Oreja de Perro es, como en el caso de Cueto, el relato familiar. De hecho, la

11 Aquí cabe notar las afirmaciones de Thays acerca de la posición social ambigua del escritor en entrevistas con Britt Diegner y José Morales Saravia en La novísima novela peruana, y su comentario que "No hay por qué hacerles caso a quienes te exigen que reflejes una realidad que quizás no te tocó o te tocó de una manera indirecta, como en mi caso" (citado en Cox 69).

Revista Iberoamericana,

Vol.

L XXXI,

Núm. $\quad 250$,

Enero-Marzo 2015, $15-30$ 
traumática historia personal del narrador ocupa el centro de la narración, de tal forma que resulta difícil sacar en claro un comentario social acerca de la zona desolada desde la que se narra la novela, ni de los personajes que la pueblan aun cuando éstos son presentados de una forma directa. El relato en sí no se propone salir del tramo narrativo individual, ya que cuenta, en primera persona, las experiencias de un periodista que llega a un pueblo ayacuchano, Oreja de Perro, para hacer un reportaje sobre una visita del presidente Alejandro Toledo para iniciar un programa de reparaciones a los afectados por la violencia política, ya en la época de la supuesta reconciliación. ${ }^{12}$ En este pueblo remoto el narrador encuentra a Jazmín, una chica embarazada con quien tendrá un breve amorío antes de volver a Lima. Sin embargo, toda esta historia del viaje laboral está impregnada de los recuerdos de la muerte reciente del hijo de cuatro años del narrador, Paulo, y la aparente separación del narrador de su esposa, Mónica. Las conmovedoras evocaciones de la pérdida de la familia llegan a pesar tanto en el imaginario de la novela que la devastación social de Oreja de Perro se convierte, sobre todo, en una invitación a reflexionar acerca del quebranto personal.

Este hecho es aun más evidente cuando se considera el formato del texto, que se asemeja a un diario. Pero este diario, a diferencia del de Adrián Ormache en La hora $a z u l$, no parece pretender una proyección pública; de esta forma, se corta la intención de comunicación interpersonal, lo que hace de la novela/diario un espacio de dolorosa introspección. Un lugar llamado Oreja de Perro ofrece, entonces, una auto-confesión, que se presenta en un registro seco y angustiado, pero no por ello menos melodramático. De hecho, la represión de la ebullición melodramática que aparece en la novela de Thays podría conectarse con la técnica del relato detectivesco "hard-boiled" -género cuyos maestros, Dashiell Hammet y Raymond Chandler, son mencionados en la novela (152)-donde el tono plano del narrador funciona en contraste con los eventos altamente afectivos que relata. En la novela de Thays, el laconismo y la tristeza en la voz narrativa son omnipresentes, y así la emoción melodramática estrictamente controlada se convierte en un aspecto clave del texto.

Este estado emocional lacónico y contenido es producto directo del relato familiar, y más específicamente, de la muerte de Paulo, un niño que padece de arranques de hiperactividad violenta; además, en distintos momentos, Paulo duerme inquieto y se despierta después de haberse mordido la lengua. Un día en que Paulo está particularmente cansado, y su padre no repara en las quejas de dolor de cabeza del hijo, ni llama al médico para que lo evalúe, el niño muere mientras duerme. En este momento se presenta esta dolorosa escena:

12 Como apunta Luis Hernán Castañeda, según el informe de la Comisión de la Verdad y Reconciliación, Oreja de Perro "se trata de una subregión del distrito ayacuchano de Chungui donde se asientan diecisiete comunidades campesinas” (270). Aunque el nombre Oreja de Perro sí aparece en el mapa, la versión del pueblo particular es ficcionalizada en la novela.

Revista Iberoamericana, Vol. LXXXI, Núm. 250, Enero-Marzo 2015, 15-30 ISSN 0034-9631 (Impreso)

ISSN 2154-4794 (Electrónico) 
El médico diagnosticó que había sufrido una trombosis durante la noche. Además, nos comentó que si no sabíamos que sufría ataques de epilepsia. Le dijimos que no. Luego nos explicó algunas cosas, algunas señales que no advertimos. Obviamente, lo de la lengua mordida era una de ellas.

¿Pudimos haberlo evitado?, preguntó Mónica.

El doctor empezó a dar una serie de explicaciones con párrafos largos, científicos, a los que Mónica y yo asentíamos, aunque sus ojos de lástima por el género humano decían cosas muy distintas (Thays 89).

Casi inmediatamente después de esta conmovedora escena, el narrador cuenta que "Lo primero que me pasó por la cabeza fue suicidarme" (Thays 89), indicando más allá de cualquier duda el comprensible estado depresivo del padre en luto. Este punto en la novela es quizás su cima melodramática por la manera en que, en medio de su lenguaje escueto, provoca fuertes sentimientos de simpatía en el lector. Pero dentro de esta tristeza hay una sensación ineludible de culpa por no haberse dado cuenta de la enfermedad del hijo, y de no haber tomado las medidas para salvarlo. La depresión del narrador que sigue a la muerte de Paulo -y la subsiguiente separación de su pareja-luego se traducirá en un proceso de autocastigo y un deseo de ver los escenarios más oscuros de la vida.

Cuenta el narrador que después de la muerte de Paulo, al crearse actividades para combatir su depresión, se vuelve experto en el cine de François Truffaut comprando, catalogando y analizando toda su obra, para luego seguir con otros directores. De hecho, la obsesión del narrador de citar referentes artísticos que se asemejan a su experiencia vital llega a ser una característica visible de la novela. Junto con estas tareas, el narrador pasa "Horas y horas frente al televisor" y cuenta que "Así fue como fui a dar con los testimonios de la Comisión de la Verdad y los miraba con vehemencia, como si fuesen un programa continuado, una serie, uno tras otro cada uno de los testimonios" (Thays 94). Es precisamente en este momento de depresión autodestructiva cuando el narrador empieza a prestar atención a los testimonios televisados de la Comisión de la Verdad y Reconciliación: "Me pasaba horas mirando las declaraciones por televisión. Reconozco que al principio lo hacía por morbo" [... "A mí el tema que me atraía era el del Mal" (Thays 16-17). Luego, a raíz de estos testimonios, el narrador cínicamente escribe un artículo periodístico "cargado de aquellas ideas que se les podrían haber ocurrido a ellos [sus lectores] también, y por eso las consideran espléndidas, inteligentes, agudas" (Thays 19), después del cual es elegido por el periódico - muy a su pesar-para cubrir el evento en Oreja de Perro.

En este sentido, es importante notar que el intenso interés del narrador por los resultados de la Comisión de la Verdad no nace necesariamente de una preocupación por los afectados por la violencia nacional, sino más bien de una compulsión obsesiva producida por la muerte del hijo. La crisis familiar típica del melodrama sigue ocupando el lugar principal de la narración y lo que terminamos leyendo en la novela son los

Revista Iberoamericana, Vol. LXXXI, Núm. 250, Enero-Marzo 2015, $15-30$ 
intentos del narrador de lidiar con este conflicto personal y el remordimiento que siente con respecto a su pasado. Así, aunque no desee viajar, el desplazamiento del narrador hacia Oreja de Perro resulta propicio ya que ofrece la posibilidad de escribir, "un modo paradójico de alejar los recuerdos, de liberarse de ellos: una purga, se diría, de la materia oscura y tóxica que se empoza en el interior de la conciencia" (Elmore 215). Pese a ello, dada la forma narrativa intimista del diario, la posibilidad del comentario social resulta ser limitada, y lo es todavía más cuando consideramos que, por un lado, lo que más le concierne al narrador en su viaje es poder escribir una carta de respuesta a Mónica, quien le había escrito anunciando su aparente intención de separarse de él; y por otro, los apuntes del narrador subrayan su ensimismamiento y falta de conexión con el entorno andino. ${ }^{13}$

La introversión del narrador es evidente en varios instantes ya que este formato escritural invita a examinarse y criticarse. Por ejemplo, cuando en una fiesta entre otros reporteros que están en Oreja de Perro para cubrir la llegada de Toledo todos comparten un mismo vaso para tomar cerveza, el narrador repara en condiciones higiénicas que le producen náuseas y reflexiona: "Me reconozco perfectamente en el sujeto que me he convertido: un tipo lleno de patologías y ascos, con fobia social, incapaz de relacionarse con los demás. Un impresentable" (Thays 145). Significativamente, un aspecto por el que el narrador se critica es su consciente personalidad melodramática y comenta que "Nunca dejaré de sentirme mal conmigo mismo. Qué meticuloso es ser melodramático, estar todo el tiempo a la expectativa de tus propios problemas y dolencias, en alerta constante como un felino amenazado" (Thays 73). Justamente en este auto-reconocimiento se entiende el aspecto tremendamente íntimo del texto, puesto que, como aquí observa el narrador, ya después de la muerte de Paulo y con el sentimiento de melancolía que esto le ha dejado, es incapaz de pensar más allá de sí mismo.

Este ensimismamiento se vuelve aparente en la novela en los momentos que el narrador pasa junto a Jazmín, su amante ayacuchana que lo provoca sexualmente y lo fastidia a la vez. La historia de Jazmín es, de hecho, donde residiría el fundamento del comentario social en Un lugar llamado Oreja de Perro, puesto que la muchacha y su familia han sido víctimas de la violencia política -su madre ha sido torturada y desaparecida por el ejército y ella está embarazada de un soldado cuya muerte marcará el final de la novela. Quizá inverosímilmente, Jazmín se siente atraída inmediatamente hacía el narrador, tratando agresivamente de seducirlo; a la vez, ella simboliza para éste un mundo andino que le es ajeno. Los momentos que comparten juntos son intensos

13 Un interesante contraste a la novela de Thays se encuentra en El material humano (2009) del guatemalteco Rodrigo Rey Rosa. Aunque las dos novelas comparten el formato del diario y también recuerdos de la vida familiar a la luz de conflictos nacionales internos, en el caso de Rey Rosa los hechos de la violencia política son los que empiezan a influir en su experiencia íntima y no viceversa como ocurre en la novela de Thays.

Revista Iberoamericana, Vol. LXXXI, Núm. 250, Enero-Marzo 2015, 15-30 ISSN 0034-9631 (Impreso)

ISSN 2154-4794 (Electrónico) 
y culminan cuando, al haber abandonado Oreja de Perro, el narrador descubre que el supuesto padre del hijo de Jazmín ha sido asesinado, lo que causa un escándalo en el pueblo que recibe al presidente. La salida del narrador de Oreja de Perro sirve nuevamente para poner en perspectiva cualquier acercamiento que pudiera haber tenido al pueblo, cuando apunta en su cuaderno "Increíble: hace tan sólo unas horas que sali de Oreja de Perro y me parece que pasaron mil años, tantos que no tengo nada que ver con ese sitio ni con nada de lo que pasó [...] Ni siquiera con Jazmín. Sin embargo, lo de Paulo parece que fue ayer, hoy mismo, hace unos minutos, en este mismo instante, y quiero matar a todo el mundo, quiero golpear a alguien" (Thays 189-90 -cursiva del autor-). La creciente distancia física refleja la distancia emocional que aumenta entre el narrador y Jazmín mientras, por otro lado, la dolorosa memoria de la pérdida del hijo sigue fresca. Así, este pasaje no puede sino subrayar la importancia fundamental del nudo afectivo familiar de la novela de Thays. Es precisamente la pérdida del hijo y el intento de lidiar con este dolor, contado en un registro controlado pero hondamente emocional, lo que orienta toda la acción de este melodrama familiar.

Como en la novela de Cueto, en la novela de Thays la idea de la unidad familiar nunca se aparta del centro del relato, pero en Un lugar llamado Oreja de Perro, el narrador está quizás más tajantemente disociado de su posible diálogo con el momento de violencia nacional. Después de haber arribado en Lima, reflexionando sobre un posible intento de interceder por Jazmín si ocurriera algún problema después de la muerte del padre de su hijo, el narrador piensa, “¿Realmente quiero salvar a Jazmín? No, no quiero hacerlo. Ni siquiera la conozco, no sé quién es, no soy responsable de ella” (Thays 211). La manera en que el narrador se lava las manos del asunto podría parecernos cercana a las reflexiones de Adrián Ormache al final de La hora azul cuando afirma "Es obvio que no voy a hacer nada por remediar esa injusticia tan enhebrada a la realidad, no puedo hacer nada, no voy a ayudarlos, a lo mejor tampoco me interesa. Y sin embargo haber sabido sobre tantas muertes y torturas y violaciones ahora me entristece tanto, y también me avergüenza un poco, no sé por qué. No voy a olvidarlos [...] Pero quizá sí. Quizá todo esto es una sensación pasajera" (Cueto, Azul 274). Aunque la novela de Cueto también demuestra una distancia problemática entre el narrador y la violencia social, también manifiesta que la violencia es una preocupación presente, mientras el narrador de Un lugar llamado Oreja de Perro parecería huir del conflicto nacional para nuevamente encerrarse en un mundo depresivo producido a raíz de la pérdida familiar.

Es en esta insistencia dolorosa y lacónica de la novela de Thays donde se revela la forma melodramática del relato. Al recurrir una y otra vez a la auto-increpación para llevar las emociones del padre en luto a un primer plano, Un lugar llamado Oreja de Perro no puede sino afectar al lector, aun cuando el registro seco de la narración parecería evitar el compromiso emocional. A través de este ensimismamiento narrativo se ofrece una visión opaca del Perú después de la violencia nacional, escenificando una división radical entre la clase media limeña y los sectores andinos más afectados por el conflicto

Revista Iberoamericana,

Enero-Marzo 2015, $15-30$ 
interno. Al final, en Un lugar llamado Oreja de Perro no hay, pues, un acercamiento directo a la violencia política. Esto, sin embargo, nos deja otro tipo de comentario social, pues el tímido intento de intervenir en el entorno andino, remarcado casi exclusivamente por un amorío con una chica lugareña, pone en escena los grandes abismos que todavía quedan por atravesarse para llegar a una reconciliación nacional más sincera.

Lo que Un lugar llamado Oreja de Perro y La hora azul nos demuestran es el empleo de la estética melodramática para comunicar perspectivas acerca de momentos conflictivos, tanto al nivel personal como social. En ambas novelas, y en distintos grados, los conflictos de familia están anclados en el ámbito nacional para conectar lo íntimo con lo público. Al narrarse desde la época de la reconciliación mientras recuerdan y reflexionan -aunque tangencialmente- acerca de la violencia nacional, las dos novelas indagan en la conciencia colectiva y lo hacen por medio del empleo de estructuras afectivas. La hora azul es más claramente intencional en este sentido, ya que los miembros de la familia están directamente implicados en la violencia nacional, mientras Un lugar llamado Oreja de Perro presenta una familia cuya tragedia ocurre al margen del conflicto armado interno. En ambos casos, el logro de estas dos obras se encuentra en la forma en que, honesta y dolorosamente, reconocen su posición de privilegio con respecto a la violencia política. De este reconocimiento nace un deseo de participar en la curación de las heridas del conflicto nacional, lo que resulta problemático precisamente por la distancia que los protagonistas de las respectivas novelas sienten entre sí mismos y el entorno andino. Al indagar en esta precaria encrucijada entre lo personal y lo político, las novelas de Cueto y Thays se insertan en un cuestionamiento de las posibilidades, los límites y las responsabilidades de la literatura social, un tema de profunda importancia en el Perú contemporáneo.

\section{BiBIOGRAFÍA}

Barthes, Roland. A Lover's Discourse: Fragments. Richard Howard, trad. New York: Hill and Wang, 1979.

Brooks, Peter. The Melodramatic Imagination: Balzac, Henry James, Melodrama, and the Mode of Excess [1976]. New Haven: Yale UP, 1995.

Castañeda, Luis Hernán. "El viaje terapéutico y la elaboración dialógica en Un lugar llamado Oreja de Perro de Iván Thays". Inti 67-68 (2008): 269-76.

Cox, Mark R. "Apuntes para el estudio de la narrativa peruana desde 1980 y la violencia política”. Pachaticray (Elmundo al revés): Testimonios y ensayos sobre la violencia politica y la cultura peruana desde 1980. Mark R. Cox, ed. Lima: Editorial San Marcos, 2004. 67-77.

Cueto, Alonso. Pálido cielo y otros relatos. Lima: Grupo Editorial Norma, 2010. La hora azul. Lima: Anagrama/Peisa, 2006.

Revista Iberoamericana, Vol. LXXXI, Núm. 250, Enero-Marzo 2015, 15-30 ISSN 0034-9631 (Impreso)

ISSN 2154-4794 (Electrónico) 
"Testimonio". Encuentro Internacional Narradores de Esta América. Jorge Cornejo Polar, ed. Lima: Universidad de Lima, 1998. 33-36.

Del Pino H., Ponciano. “Family, Culture, and 'Revolution': Everyday Life with Sendero Luminoso." Shining and Other Paths: War and Society in Peru, 1980-1995. Steve J. Stern, ed. Durham: Duke UP, 1998. 158-92.

Diegner, Britt y José Morales Saravia. La novísima novela peruana. Lima: Editorial San Marcos, 2006.

Elmore, Peter. "El viaje al interior”. Hueso Húmero 53 (2009): 212-17.

Elsaesser, Thomas. "Tales of Sound and Fury: Observations on the Family Melodrama." Home Is Where the Heart Is: Studies in Melodrama and the Woman's Film. Christine Gledhill, ed. London: British Film Institute, 1987. 43-69.

Faverón Patriau, Gustavo, ed. Toda la sangre: Antología de cuentos peruanos sobre la violencia política. Lima: Grupo Editorial Matalamanga, 2006.

Gerassi-Navarro, Nina. Pirate Novels: Fictions of Nation Building in Spanish America. Durham: Duke UP, 1999.

Martín-Barbero, Jesús. De los medios a las mediaciones: Comunicación, cultura y hegemonía. México: Ediciones G. Gili, 2001.

Rey Rosa, Rodrigo. El material humano. Barcelona: Anagrama, 2009.

Ruz, Robert. Contemporary Peruvian Narrative and Popular Culture: Jaime Bayly, Iván Thays and Jorge Eduardo Benavides. Woodbridge: Tamesis, 2005.

Thays, Iván. Un lugar llamado Oreja de Perro. Barcelona: Anagrama, 2008.

Entrevista con Jaime Cabrera Junco. Peru21.com. 18 de enero 2012. Web. 25 marzo 2012.

Vich, Victor. "Violencia, culpa y repetición: La hora azul de Alonso Cueto". Contra el sueño de los justos: La literatura peruana ante la violencia política. Juan Carlos Ubilluz, Alexandra Hibbetty Victor Vich, eds. Lima: Instituto de Estudios Peruanos, 2009. 233-46. 